\title{
Assessment of autonomic function in myotonic dystrophy
}

\author{
Jan C den Heijer, J Gert van Dijk, Ward L E M Bollen, Jelte E Bos, Axel R Wintzen
}

\begin{abstract}
Published reports suggested autonomic nervous system dysfunction in myotonic dystrophy but were inconclusive partly due to small patient numbers and because only a limited number of tests was used. Autonomic nervous system function with noninvasive tests was assessed in ten myotonic dystrophy patients and age and sex matched healthy controls. Statistically significant differences included reduction in the heart rate response to standing and in the blood pressure response to sustained handgrip. Latency of the pupillary light reflex was not different from controls but the time to reach peak velocity of contraction was significantly longer in the myotonic dystrophy group. It is argued that these results reflect dysfunction of voluntary and iris smooth muscle rather than autonomic nervous system dysfunction.
\end{abstract}

A number of reports have been published concerning autonomic nervous system function in myotonic dystrophy. Myotonic dystrophy is an autosomal dominantly inherited multi-system disorder. Weakness, wasting and myotonia of skeletal muscle are the most prominent signs. Others include lenticular opacities, mental deterioration and hypersomnia, endocrine disturbances, skeletal abnormalities and cardiac conduction disturbances. ${ }^{1}$ Whether autonomic nervous system dysfunction should be added has remained unclear since proposed causes for observed abnormalities vary considerably.

Mass and Patterson reviewed clinical phenomena suggesting autonomic nervous system dysfunction: hyperhidrosis, excessive sialorrhea and lacrimation, defective vasoconstriction and sluggish pupillary reactions to light. $^{2}$ They presented these without firm supporting evidence as abnormalities of involuntary muscle.

Thomson et al using the electronic pupillograph of Lowenstein and Loewenfeld performed measurements of the pupillary light reflex in 15 patients with myotonic dystrophy and found an increased mean latency (325 versus a normal $250 \mathrm{~ms}$ ). They also described a tendency of peak speed of contraction to occur later, to be diminished and to be maintained longer than normal but exact figures were not given. They used the term "sluggish" to describe these abnormalities and reported pupillary reactions to near vision to be equally "sluggish". They suggested a midbrain lesion as the cause. ${ }^{3}$ Spaide found defective pupillary dilation in darkness in two patients and proposed a preganglionic sympathetic lesion. ${ }^{4}$

Mechler and Mastaglia reported abnormal vascular adrenergic receptor responses in skeletal muscle showing weakness in five patients. ${ }^{5}$ They give as possible explanations either a cell membrane defect of vascular smooth muscle cells or an adaptive change to meet the functional and metabolic needs of myotonic muscle.

Pathological evidence for involvement of the autonomic nervous system in myotonic dystrophy was presented by Weil and Keschner. ${ }^{6}$ They described severe atrophy of the lateral columns of the spinal cord in one patient. This patient also had tuberculous meningitis and high-grade glioma of the brain. Later neuroanatomical studies in myotonic dystrophy patients did not confirm their findings. ${ }^{7}$

Bird et al studied pupil size, light reflex and $R$-top interval variation in the electrocardiogram (ECG-RR variation) during deep breathing in five patients. ${ }^{8}$ They found diminished ECG-RR variation in one patient and increased light reflex latency in three patients and stressed the necessity of using additional tests in more patients to clarify the extent and severity of autonomic nervous system involvement in myotonic dystrophy. Aminoff et al tested several cardiovascular reflexes in eight patients, seven of whom had symptoms suggestive of autonomic nervous system dysfunction. ${ }^{9}$ Results were reported to be normal but no details were given.

The question thus remains unanswered whether there is autonomic nervous system involvement in myotonic dystrophy or whether abnormalities found in autonomic nervous system function tests are to be explained otherwise. This prompted us to undertake this study.

\section{Subjects and methods}

Ten patients (four females, six males) with characteristic clinical features of myotonic dystrophy and a positive family history for the disease were studied with their informed consent. Patients had neither signs nor symptoms suggesting other neurological disorders. Medication had not been changed for at least three months preceding the tests (table 1). Patients were compared with healthy age and sex matched controls. 

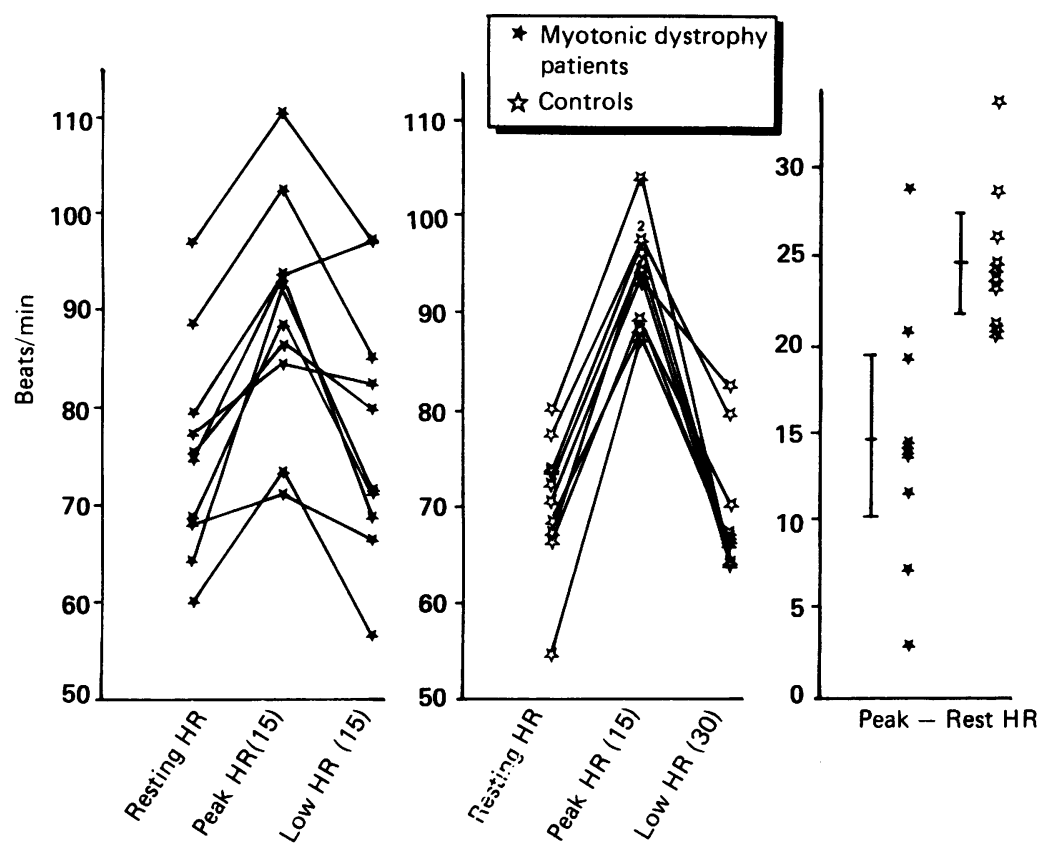

Figure 1 Heart rate response to standing up (30:15 ratio). bts/min: beats per minute; HR: heart rate; Bar in third panel: Mean $\pm 95 \%$ confidence interval.

A standardised questionnaire was used to screen for symptoms suggesting autonomic nervous system dysfunction focusing on orthostatic hypotension, sweating, sexual function, micturition and defaecation.

Only noninvasive tests were applied. ${ }^{10}$ These were described in more detail elsewhere ${ }^{11}$ and included:

Resting heart rate variation, ${ }^{12}{ }^{13}$ heart rate variation while breathing at a rate of six to eight minutes $^{14}$

In both tests the ratio of the longest ECG-RR interval to the shortest out of 120 beats (max:min ratio) was calculated.

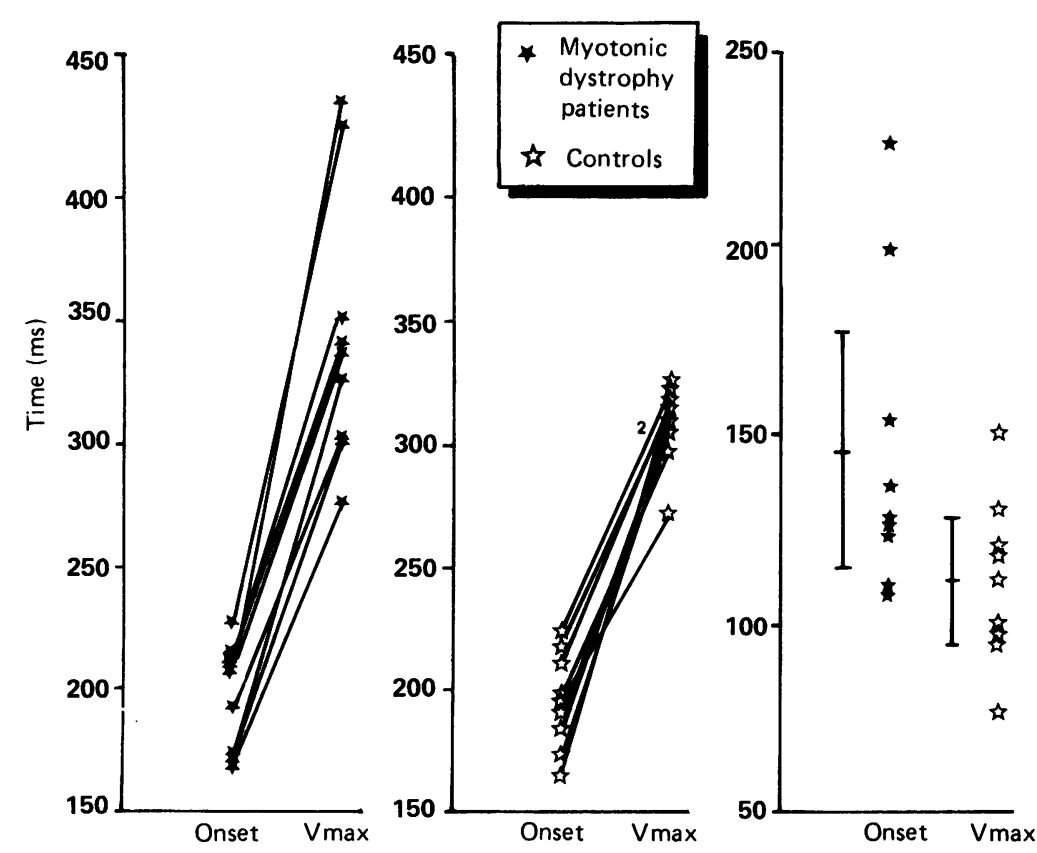

Figure 2 Pupillary light reflex. Onset: Latency of onset of constriction after start of light stimulus. Vmax: Latency of maximal velocity of constriction after start of light stimulus. Bar in third panel: Mean $\pm 95 \%$ confidence interval.
Heart rate response to standing $u p^{1415}$

The ratio of the longest ECG-RR interval around beat 30 to the shortest around beat 15 after rising from a supine position (modified 30:15 ratio) was determined.

Heart rate response to the Valsalva manoeuvre ${ }^{16}$ The ratio of the longest ECG-RR interval after the manoeuvre to the shortest during the manoeuvre was assessed. Calculations were made online on the basis of computer analysis of the ECG signal with a sample frequency of $200 \mathrm{~Hz}$. All heart rate variation tests were performed twice and the mean values of the two tests were recorded.

Blood pressure fall to standing $u p^{17}$

The difference between systolic pressure in the supine position and one minute after standing up was recorded.

Blood pressure rise to sustained handgrip ${ }^{18}$

Maximum diastolic blood pressure rise on sustained handgrip at $30 \%$ of maximum voluntary contraction for up to five minutes was determined.

Pupillary light reflex latency measurement ${ }^{19}$

This was performed using an infrared reflection detection system built into a spectacle frame. Signals were stored on tape and computerprocessed offline with a temporal resolution of $5 \mathrm{~ms}$.

Sympathetic skin response on both hands and feet $^{20}$

The response depends upon reduction of skin resistance to current as a result of sweating and was elicited by an electrical startling stimulus and recorded using EMG surface electrodes.

Nerve conduction velocity (NCV) measurements Using surface electrodes motor NCV was assessed in median, tibial and peroneal nerves. Sensory NCV was measured in median, ulnar and sural nerves. H-reflex and ankle-reflex latencies were determined. Results were compared with normal values from our laboratory. Patients and controls were compared using Wilcoxon's rank sum test. Two sided p-values were calculated and differences considered significant when $\mathrm{p}<0.05$.

\section{Results}

The questionnaire revealed that two patients had symptoms suggesting orthostatic hypotension, one claimed complete absence of sweating, three had loss of libido, four complained of incontinence for urine and one had diarrhoea with incontinence for faeces (table 1).

Heart rate variation at rest and during forced breathing did not differ between the two groups. The 30:15 ratio was significantly lower in the patient group. The Valsalva ratio in the patient group was also lower $(0.05<\mathrm{p}<0.1)$.

Blood pressure fall on standing up was within normal limits. Diastolic blood pressure rise to sustained handgrip was significantly lower in the patient group. One patient could not perform a satisfactory handgrip and was excluded.

The sympathetic skin response was present in all four limbs in all subjects except one patient who had had a lumbar sympathectomy dysbasia and showed no responses on either foot. 


\begin{tabular}{|c|c|c|c|c|c|c|c|c|c|c|c|c|c|c|c|}
\hline \multirow[b]{3}{*}{ Patient } & \multirow[b]{3}{*}{ Sex } & \multirow[b]{3}{*}{ Age (years) } & \multirow[b]{3}{*}{ Medication } & \multicolumn{12}{|c|}{ Clinical data } \\
\hline & & & & \multicolumn{3}{|c|}{ Muscular } & \multicolumn{5}{|c|}{ Autonomic } & \multicolumn{4}{|c|}{ Other } \\
\hline & & & & $W$ & $A$ & $M$ & $D$ & $L$ & $S$ & $I$ & $D i$ & $H$ & $C$ & $T$ & Co \\
\hline 1 & $\mathbf{F}$ & 52 & Digoxin & + & + & + & + & & & & & + & + & & + \\
\hline 2 & $\mathrm{~F}$ & 45 & None & + & + & + & & & & & & + & & & + \\
\hline 3 & $\mathrm{~F}$ & 40 & None & + & + & + & + & & & + & & & & & \\
\hline 4 & $\mathrm{~F}$ & 24 & None & + & + & + & & & & & & + & + & & + \\
\hline 5 & $\mathbf{M}$ & 61 & None & & & & & + & + & + & & + & + & + & + \\
\hline 6 & $\mathbf{M}$ & 49 & None & + & & & & + & & + & & + & & & \\
\hline 7 & $\mathbf{M}$ & 45 & $\begin{array}{l}\text { Fenprocoumon } \\
\text { Clofibrate }\end{array}$ & + & + & + & & + & & & & + & & + & \\
\hline 8 & $\mathbf{M}$ & 35 & None & + & + & + & & & & & & + & + & + & \\
\hline 9 & $\mathbf{M}$ & 34 & None & + & + & + & & & & & & + & & + & \\
\hline 10 & $\mathbf{M}$ & 20 & None & + & + & + & & & & + & + & + & & & \\
\hline \multicolumn{3}{|c|}{$\begin{array}{l}\text { Mean (SD) } \\
\text { Controls }\end{array}$} & $\begin{array}{l}40 \cdot 5(12 \cdot 6) \\
39 \cdot 5(11 \cdot 3)\end{array}$ & & & & & & & & & & & & \\
\hline
\end{tabular}

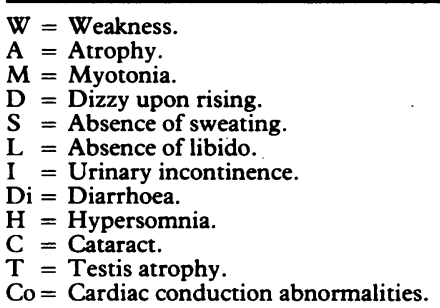

As no asymmetries in pupillary light reflex latency between left and right eyes were found data from both eyes were pooled. Values in myotonic dystrophy patients did not differ from controls (table 2).

Results of the nerve conduction velocity studies were within the normal range in al patients.

\section{Discussion}

As pupillary light reflex latency did not differ between myotonic dystrophy patients and controls there seems to be no indication of nervous involvement at this level. We could, however, confirm the finding of Thompson et al that time lag between pupillary reflex onset and peak velocity of contraction is increased (fig 2 ). This is best explained by invoking iris smooth muscle involvement. Evidence of smooth muscle involvement in the gastrointestinal and urinary tract in myotonic dystrophy based on experimental work has been given by Collins Harvey et al. ${ }^{21}$ Mechler and Mastaglia ${ }^{5}$ found indication of vascular smooth muscle abnormalities and suspected them to be yet another manifestation of a widespread defect of cell membranes in myotonic dystrophy. ${ }^{22}$ We feel that the abnormalities found in the pupillary light reflex test fit well into this concept.
Under our test conditions (quiet supine rest) heart rate variation at rest and during forced breathing depends predominantly on vagal reflexes: afferent from pulmonary stretch receptors running in the vagal nerves ${ }^{23}$ and efferent vagal innervation of the heart. ${ }^{24}$ As results from these tests were normal we assumed these pathways to be intact.

Impulses causing heart rate variation to standing up (30:15 ratio) come partly from proprioceptive afferents of the muscles involved in the effort of standing up and in part from arterial and cardiac baroreceptors. ${ }^{25}$ As the response can be abolished by atropine and is unaffected by propranolol the efferent limb of the reflex arc is the vagal innervation of the heart. ${ }^{12}{ }^{15}$ As these efferent pathways were found to be intact the cause for the diminished reaction should be located in the afferent limb or in the central part. If baroreceptor impulses were deficient or central processing of these impulses disturbed, an exaggerated postural fall in blood pressure would be expected. However, no difference in blood pressure response to standing up was found between patients and controls. On the other hand myotonic dystrophy patients had significantly less muscular strength in the sustained handgrip test than controls $(22 \pm 13.6$ versus $42 \cdot 2 \pm$ g kgf; p $<0.01)$. Although handgrip strength

Table 2 Results of autonomic function tests

\begin{tabular}{|c|c|c|c|c|c|}
\hline \multirow[b]{2}{*}{ Tests } & \multirow[b]{2}{*}{ Expressed in } & \multirow[b]{2}{*}{$N$} & \multirow{2}{*}{$\frac{\text { Patients }}{\text { Mean (SD) }}$} & \multicolumn{2}{|l|}{ Controls } \\
\hline & & & & Mean $(S D)$ & $p^{\star}$ \\
\hline $\begin{array}{l}\text { Heart rate variation } \\
\text { Resting } \\
\text { Breathing 6-8/minutes } \\
\text { Standing } \\
\text { Valsalva's manoeuvre } \\
\text { BP resp to standing up } \\
\text { BP resp to sust handgrip } \\
\text { Maximal handgrip force } \\
\text { PLR Onset latency } \\
\text { PLR Onset-Vmax latency }\end{array}$ & $\begin{array}{l}\text { Ratio } \\
\text { Ratio } \\
\text { Ratio } \\
\text { Ratio } \\
\text { mm Hg (syst) } \\
\text { mm Hg (diast) } \\
\text { Kgf } \\
\text { ms } \\
\text { ms }\end{array}$ & $\begin{array}{r}10 \\
9 \\
10 \\
9 \\
10 \\
9 \\
9 \\
9 \\
9\end{array}$ & $\begin{aligned} 1.23 & (0.08) \\
1.45 & (0.15) \\
1.17 & (0.13) \\
1.52 & (0.28) \\
-5.5 & (12) \\
16 & (7) \\
22.0 & (13.6) \\
201 & (27) \\
145 & (40)\end{aligned}$ & $\begin{aligned} 1.32 & (0.15) \\
1.57 & (0.22) \\
1.40 & (0.15) \\
1.82 & (0.33) \\
-3.5 & (4) \\
29.5 & (8) \\
41.8 & (9 \cdot 1) \\
193 & (19) \\
111 & (22)\end{aligned}$ & $\begin{array}{l}\text { NS } \\
\text { NS } \\
\mathrm{p}<0.01 \\
\mathrm{p}<0.1 \\
\mathrm{NS} \\
\mathrm{p}<0.01 \\
\mathrm{p}<0.01 \\
\mathrm{NS} \\
\mathrm{p}<0.05\end{array}$ \\
\hline
\end{tabular}

$\mathrm{p}^{\star}=\mathrm{p}$ values of Wilcoxon's ranksum test; $\mathrm{BP}$ resp $=$ blood pressure response; PLR $=$ pupillary light reflex; Vmax $=$ maximal velocity; Further explanation in text. 
and 30:15 ratio were only weakly correlated we concluded that the abnormal $30: 15$ ratio in myotonic dystrophy patients was probably caused by diminished input from proprioceptive muscle afferents. Consequently the difference would be expected to lie in the exercisedependent first part of the response. This appeared to be the case: the rise in heart rate from resting to peak level (around beat 15) was significantly less in myotonic dystrophy patients (Peak rate minus Rest rate: $14.5 \pm 7$ versus $24 \pm 4$ beats per minute; $p<0.01$ ) while Rest minus Low (around beat 30 ) rate was similar to that in controls $(-2 \pm 7$ versus 2 \pm 10 beats per minute). See fig 1 .

During Valsalva's manoeuvre afferent impulses probably come from proprioceptive muscle afferents, baroreceptors as well as from pulmonary stretch receptors. ${ }^{26}$ Again the efferent limb of the reflex arc mainly consists of the vagal cardiac innervation. ${ }^{27}$ As the afferants in this test are a combination of those in the previous tests it would be expected that the Valsalva ratio in myotonic dystrophy patients would be abnormal but to a lesser degree than the 30:15 ratio. This was exactly what we found.

The rise in blood pressure during isometric exercise is the cumulative effect of a heart ratedependent increase in cardiac output and of peripheral vasoconstriction both mediated by sympathetic innervation on $\beta$ and $\alpha$-adrenoceptors respectively. ${ }^{18}$ The afferent pathways of this reaction consists of proprioceptive afferents from the exercising muscles and of the central command from higher centres to these muscles. $^{28}$ Thus blood pressure rise not only depends on effort, which was kept fairly uniform by demanding contraction at $30 \%$ of maximal voluntary contraction, but also on muscular power. If we adopt the normal values given by Ewing et $a l^{18}$ the formula for the expected diastolic blood pressure rise in $\mathrm{mm}$ $\mathrm{Hg}$ is: $10.604+0.51 \times$ maximal handgrip force in kgf (as in table 2). We applied this formula to our results. In myotonic dystrophy patients the expected value was $21 \cdot 8$, and the observed value $16.1 \mathrm{~mm} \mathrm{Hg}$. In the controls the expected value was 31.7 and the observed value was 29.4. These figures do not allow for testing of statistical significance but the wide range of the $95 \%$ confidence intervals in the cited article (exact figures were not included) suggests that these differences are not significant. The diminished blood pressure rise to isometric exercise can therefore be explained entirely by diminished input from muscle afferents and does not signify autonomic nervous system dysfunction.

Further indication for intact sympathetic function is the normal blood pressure response to standing up, in which the efferent pathways are the same as in the blood pressure response to isometric exercise. The normal sympathetic skin response in all patients, which is a measure for the functional integrity of the sympathetic sudomotor system, points in the same direction. ${ }^{29}$

We conclude that the abnormalities in the pupillary reflex in myotonic dystrophy are caused by iris smooth muscle involvement, and that cardiovascular reflex disturbances can be explained satisfactorily by voluntary muscle involvement; the autonomic nervous system is probably normal in myotonic dystrophy.

1 Harper PS. Myotonic Dystrophy. Philadelphia: WB Saunders, 1979.

2 Mass O, Patterson AS. Dystrophia myotonica as a generalized disease. Monatschr für Psychiatr und Neurol 1947; 113:79-99.

3 Thompson HS, Van Allen WM, von Noorden GK. The pupil in myotonic dystrophy. Invest Ophthalmol Vis $\mathrm{Sci}$ 1964;3:325-8.

4 Spaide R. Decreased sympathetic stimulation to the pupils in two patients with myotonic dystrophy. Ann Ophthalmol in two patients

5 Mechler F, Mastaglia FL. Vascular adrenergic receptor responses in skeletal muscle in myotonic dystrophy. Ann Neurol 1981;9:157-62.

6 Weil A, Keschner M. Ein beitrag zur klinik und pathologie der dystrophia myotonica. Ztschr $f$ d ges Neurol Psychiat 1927;108:687-702.

7 Berthold $\mathrm{H}$. Zur pathologischen anatomie der dystrophia myotonica (Curschmann-Steinert). Deutsche Zeitschrift für Nervenheilkunde 1958;178:394-412.

8 Bird TD, Reenan AM, Pfeifer M. Autonomic nervous system function in genetic neuromuscular disorders: hereditary motor-sensory neuropathy and myotonic dystrophy. Arch Neurol 1984;41:43-46.

9 Aminoff MJ, Beckley DJ, Mcllroy MB. Autonomic function in myotonic dystrophy. Arch Neurol 1985;42:16.

10 McLeod JG, Tuck RR. Disorders of the autonomic nervous system: pt 2. Investigation and treatment. Ann Neurol system: pt 2. In

11 den Heijer JC, Bollen WLEM, Reulen JPH, et al. Autonomic nervous function in Huntington's disease. Arch Neurol 1988;45:200-203.

12 Ewing DJ. Practical bedside investigation of diabetic autonomic failure. In: Bannister R, ed. Autonomic failure. $A$ textbook of clinical disorders of the autonomic nervous system. Oxford: Oxford University Press, 1983:371-405.

3 Wieling W, Brederode JFM, de Rijk LG, Borst C, Dunning AJ. Reflex control of heart rate in normal subjects in relation to age: $A$ data base for cardiac vagal neuropathy. Diabetologia 1982;22:163-6.

14 Page NM, Watkins PJ. The heart in diabetes: Autonomic neuropathy and cardiomyopathy. J Clin Endocrinol Metab 1979;6:377-88.

15 Ewing DJ, Campbell IW, Murray A, et al. Immediate heart rate response to standing: simple test for autonomic rate response to standing: simple test for
neuropathy in diabetes. $B M J 1978 ; \mathbf{i}: 145-7$.

16 Ewing DJ, Campbell IW, Burt AA, Clarke BF. Vascular reflexes in diabetic autonomic neuropathy. Lancet 1973; ii: $1354-6$.

17 Thomas JE, Schirger A, Fealy RD, Sheps SG. Orthostatic hypotension. Mayo Clin Proc 1981;56:117-25.

8 Ewing DJ, Irving JB, Kerr F, et al. Cardiovascular responses to sustained handgrip in normal subjects and in patients with diabetes mellitus: a test of autonomic dysfunction. Clin Sci Molec Med 1974;46:295-306.

19 Reulen JPH, Marcus TJ, van Gilst MJ, et al. Stimulation and recordings of dynamic pupillary reflex: the IRIS

20 Shahani BT, Halperin JJ, Boulu P, Cohen J. Sympathetic skin response: a method of assessing unmyelinated axon dysfunction in peripheral neuropathies. $J$ Neurol dysfunction in peripheral neuropat

21 Collins Harvey J, Sherbourne DH, Siegel CI. Smooth muscle involvement in Myotonic Dystrophy. JAMA muscle involve

22 Rüdel R, Lehmann-Horn F. Membrane Changes in Cells from Myotonia Patients. Physiol Rev 1985;65: $310-56$

23 Paintal AS. Vagal Sensory Receptors and their Reflex Effects. Physiol Rev 1973;53:159-227.

24 Pfeifer MA, Cook D, Brodsky J, et al. Quantitative Evaluation of Cardiac Parasympathetic Activity in Normal and Diabetic Man. Diabetes 1982;31:339-45.

25 Borst C, Wieling W, van Brederode JFM, Hond A, de Rijk LG, Dunning AJ. Mechanisms of initial heart rate response to postural change. Am J Physiol 1982;243: ponse to

26 Korner PI, Tonkin AM, Uther JB. Reflex and mechanical circulatory effects of graded Valsalva manoeuvres in man. $J$ Appl Physiol 1976;40:434-40.

27 Spodick DH, Meyer MB, Quarry-Pigott VM. Effect of $\beta$ adrenergic blockade on beat-to-beat response to Valsalva manoeuvre. Br Heart J 1974;36:1082-6.

28 Goodwin GM, McCloskey DI, Mitchell JH. Cardiovascular and respiratory responses to changes in central command and respiratory responses to changes in central command during isometric exercise
Physiol 1972;226:173-90.

29 Satchell PM, Seers CP. Evoked skin sympathetic responses in man. J Neurol Neurosurg Psychiatry 1987;50:1015-21. 